Article

\title{
High-Molecular-Weight Polyphenol-Rich Fraction of Black Tea Does Not Prevent Atrophy by Unloading, But Promotes Soleus Muscle Mass Recovery from Atrophy in Mice
}

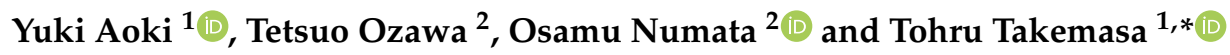 \\ 1 Graduate School of Comprehensive Human Sciences, University of Tsukuba, 1-1-1 Tennodai, \\ Tsukuba 305-8574, Japan \\ 2 Graduate School of Life and Environmental Sciences, University of Tsukuba, 1-1-1 Tennodai, \\ Tsukuba 305-8572, Japan \\ * Correspondence: takemasa.tohru.gm@u.tsukuba.ac.jp; Tel./Fax: +81-29-853-2622
}

Received: 2 August 2019; Accepted: 3 September 2019; Published: 6 September 2019

\begin{abstract}
Previously, we reported that polyphenol-rich fraction (named E80) promotes skeletal muscle hypertrophy induced by functional overload in mice. This study indicates that E80 has potential for affecting skeletal muscle mass. Then, we evaluate the effect of E80 on atrophic and recovery conditions of skeletal muscle in mice. Hindlimb suspension (unloading) and relanding (reloading) are used extensively to observe disuse muscle atrophy and subsequent muscle mass recovery from atrophy. Eight-week old C57BL/6 mice were fed either a normal diet or a diet containing 0.5\% E80 for two weeks under conditions of hindlimb suspension and a subsequent 5 or 10 days of reloading. We found that $\mathrm{E} 80$ administration did not prevent atrophy during hindlimb suspension, but promoted recovery of slow-twitch (soleus) muscle mass from atrophy induced by hindlimb suspension. After five days of reloading, we discovered that phosphorylation of the Akt/mammalian target of rapamycin (mTOR) pathway proteins, such as Akt and P70 ribosomal protein S6 kinase (S6K), was activated in the muscle. Therefore, E80 administration accelerated mTOR signal and increased protein synthesis in the reloaded soleus muscle.
\end{abstract}

Keywords: black tea; polyphenol; hindlimb suspension; reloading; mTOR

\section{Introduction}

Tea beverage such as green tea and black tea comprises leaves of Camellia sinensis. Its history is extensive and people in Asia have used tea for about 4000 years [1,2]. Recent studies indicate that low-molecular-weight tea polyphenol, such as catechins and theaflavins, have various beneficial effects. Concerning the effects of tea polyphenols on skeletal muscle, they improve endurance capacity [3], glucose uptake [4], and reduction of Endoplasmic reticulum (ER) stress [5]. They also play a part in the prevention of disuse skeletal muscle atrophy [6,7]. These reports suggest that tea polyphenol can be a candidate for improving skeletal muscle metabolism and maintaining muscle mass.

Skeletal muscle is a highly plastic tissue and responds well to environmental and physiological stimulations [8]. Overloading or unloading alter skeletal muscle mass, which is determined by the rates of both protein synthesis and degradation. Higher rates of protein degradation compared with those of synthesis within muscle result in a decrease in muscle mass (atrophy). On the other hand, higher rates of protein synthesis compared with those of degradation stimulate an increase in muscle mass (hypertrophy) [9]. Unloading, such as inactivity or space flight, causes disuse muscle atrophy in humans $[10,11]$. In rodents, the hindlimb unloading (HU) model is used extensively to observe disuse 
muscle atrophy, including molecular events [12]. The HU model is also useful in evaluating recovery responses from atrophy by relanding its legs (reloading (RE)) [12].

Muscle atrophy is characterized by decreases in muscle mass, the myofiber cross-sectional area (CSA) $[13,14]$. Subsequent mechanical reloading induces muscle regrowth. Importantly, disuse muscle atrophy, induced by such as inactivity or spaceflight, is a crucial clinical matter because impaired skeletal muscle strength can extend the duration of hospital care and result in exercise limitation, as well as spoil quality of life (QOL) [15]. Furthermore, the potential to prevent recovery of muscle mass after atrophy is of great clinical importance because impaired or retarded muscle regrowth can have severe consequences for functional performance $[16,17]$. Thus, prevention of muscle atrophy and acceleration of muscle mass recovery are indispensable for maintaining QOL.

Previously, we reported that high-molecular-weight polyphenol-rich fraction ("E80") from black tea promotes hypertrophy and activates the mammalian target of rapamycin (mTOR) signal, which regulates protein synthesis within functional overloaded skeletal muscle in mice [18]. This result indicates that E80 increases skeletal muscle mass and also stimulates protein synthesis with mechanical overload. Thus, we assessed whether E80 prevents muscle atrophy induced by HU or urges recovery of atrophied muscle mass induced by mechanical reloading.

\section{Results}

\subsection{E80 Has No Effect on Food Intake and Growth}

We used E80 extracted from the same batch of the previous report; the component of E80 is shown there [18]. The extracts were stored in dark conditions at less $20^{\circ} \mathrm{C}, 50 \%$ humidity for 10 months. The feature of E80 is a slight amount of caffeine (0.38\%) (Figure S1). A high dose of caffeine causes severe symptoms [19]; therefore, tea extract containing caffeine is unsuitable for utilization as a supplement. We performed the same experiment twice during this period. The contents of E80 were considered to be exceedingly consistent for this duration, because Shiming $\mathrm{Li}$ et al. demonstrated that tea extracts are very stable under conditions of room temperature $\left(27^{\circ} \mathrm{C}\right)$ and $60 \%$ humidity [20]. They showed that tea polyphenols such as epigallocatechin gallate (EGCG) and theaflavin are not oxidized or degraded for 360 days at conditions of $27^{\circ} \mathrm{C}$ and $60 \%$ humidity [20]. Flavanol glycosides are also consistent in dark conditions [21]. Hence, we consider that contents of E80 were the same as those in the previous study. As we reported previously [18], there was no difference in body weight between Normal and E80 among all groups (HU, RE5, and RE10) (Figure 1a). There was also no difference in food consumption between Normal and E80 among all groups (HU, RE5, and RE10) (Figure 1b). These data show that E80 intake alone does not affect food consumption and body growth, as we reported previously.
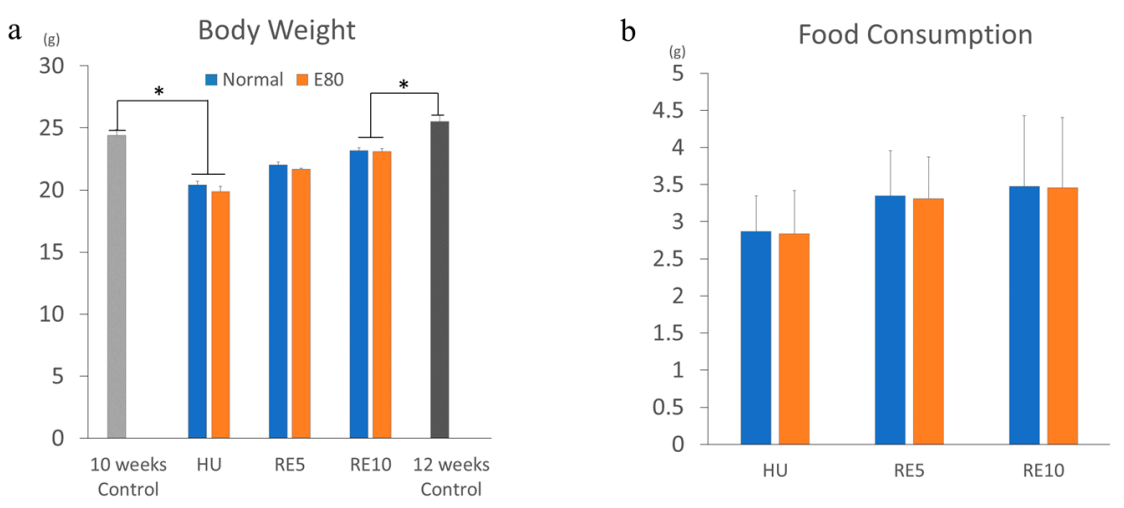

Figure 1. E80 has no effect on food intake and growth. Body weight change during hindlimb unloding (HU) and reloading (a); and food consumption per day (b) between hindlimb unloding (HU), 5-day or 10-day of reloading (RE5, RE10), and control (10 weeks or 12 weeks control). Values are presented as mean $\pm \operatorname{SEM}(n=6-7) .{ }^{*}$ indicates significant difference $(p<0.05)$. 


\subsection{E80 Does Not Prevent HU-Induced Muscle Atrophy}

In order to evaluate the effect of E80 on HU-induced atrophy, we compared the wet mass of soleus muscle, the wet weight of soleus muscle/body weight, and the CSA of soleus muscle between the Normal and the E80 of the HU group, because HU exerts the greatest atrophic effects on antigravity muscles such as the soleus muscle [12,22]. The wet mass of soleus reduced drastically by approximately $50 \%$ compared with the 10-week control (equivalent age to HU groups) after two weeks of HU, as previously reported [12,23] (Figure 2a). However, there was no difference between Normal and E80 in the HU group (Figure 2a). There were also no changes in the soleus wet mass/body weight ratio in the HU group (Figure 2b). Concerning the CSA, thickness of the fibers significantly decreased in both Normal and E80 of the HU group, compared with the 10-week control (equivalent age to HU groups), but no significant difference was observed between Normal and E80 (Figure 2c). In addition, the shape of the fiber distribution was quite similar between Normal and E80 of the HU group (Figure 2d). These results suggest that $\mathrm{E} 80$ had no effect on preventing disuse muscle atrophy and on body weight reduction during $\mathrm{HU}$.
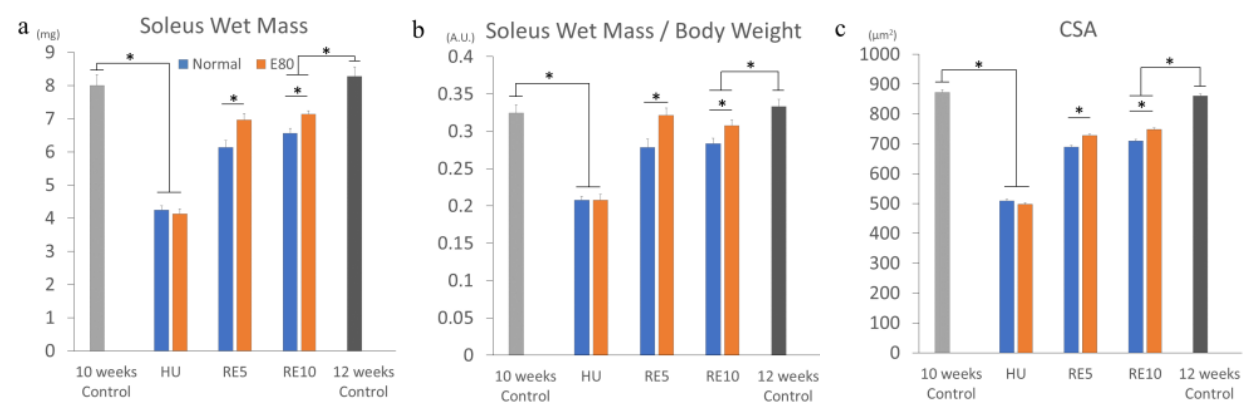

d $(\%)$

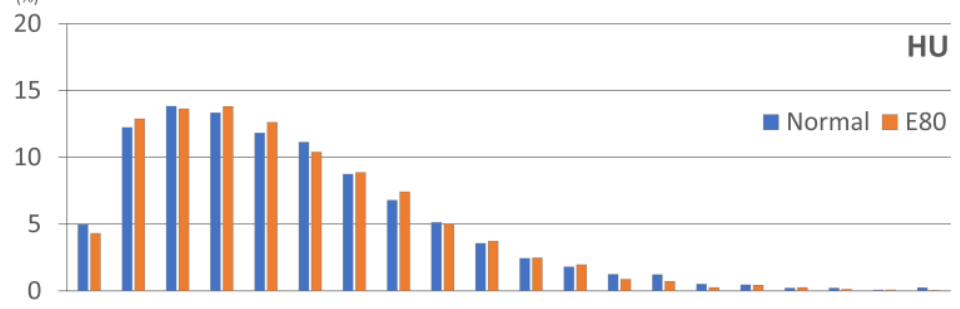

e (\%)

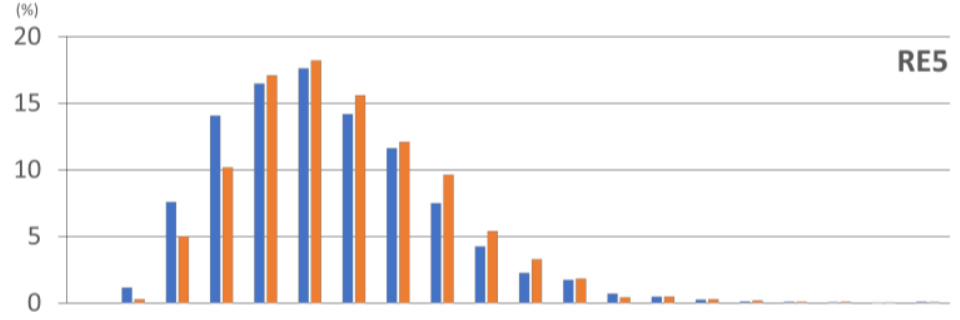

f $(\%)$

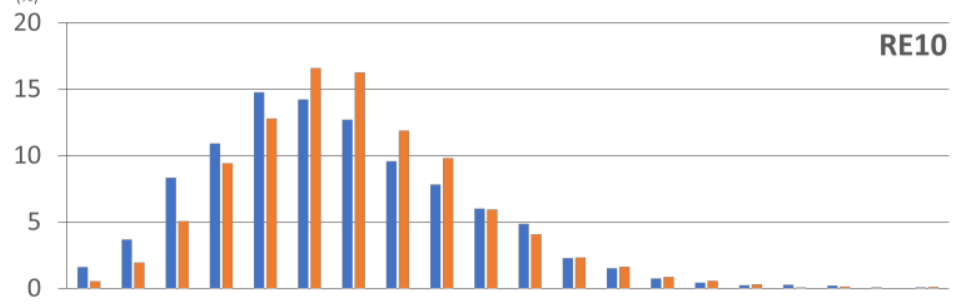

Figure 2. Cont. 


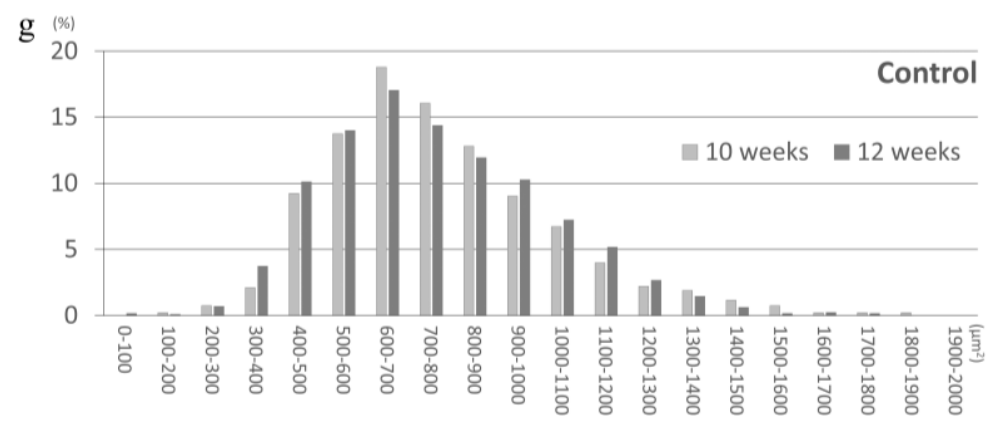

Figure 2. E80 did not prevent HU-induced atrophy, but promoted recovery of muscle mass. Muscle wet mass (a), muscle wet mass/body weight (b), cross-sectional area (c), and distribution of fibers $(\mathbf{d}-\mathbf{g})$ of soleus muscle of HU, RE5, RE10, and control groups (g). * indicates significant difference $(p<0.05)$ $(n=6-7)$. CSA, cross-sectional area.

\subsection{E80 Promotes Muscle Mass Recovery from HU-Induced Atrophy}

Subsequently, we analyzed reloaded RE5 and RE10 groups. The soleus wet mass of the RE5 and RE10 groups increased compared with the HU group (Figure 2a). In particular, the muscle mass of E80 of RE5 and RE10 significantly boosted. Similarly, the soleus wet mass/body weight ratio and CSA regained higher compared with those of the HU group (Figure 2b,c). Moreover, administration of E80 promoted recovery of the wet mass/body weight ratio and the CSA compared with Normal in the RE5 and RE10 groups (Figure 2b,c). Consistent with the CSA data, fiber distribution of the E80 group of RE5 (hereafter, described as RE_E80) was shifted rightward. In particular, the number of fibers above $700 \mu \mathrm{m}^{2}$ was further increased compared with RE5_Normal (Figure 2e). As RE5, E80 of RE10 group has thicker fibers ( 800 to $900 \mu \mathrm{m}^{2}$, above average) than Normal (Figure 2f). These data indicate that administration of E80 promoted the restoration of skeletal muscle mass from disuse muscle atrophy induced by HU. To be certain, we compared mice between age at beginning (10 weeks old) and at the end (12 weeks old) of this experiment, and the CSA and fiber distribution between the two groups were almost the same (Figure 2c,g).

\subsection{E80 Activates the Akt/mTOR Pathway During Reloading}

Skeletal muscle hypertrophy, an increase in skeletal muscle mass and CSA, is considered to be a result of enhanced protein synthesis. The major pathway regulating protein synthesis in skeletal muscle is the insulin-like growth factors (IGF)/mTOR signal [9]. Phosphorylation of Akt encourages protein synthesis in the skeletal muscle [9]. Moreover, phosphorylated Akt promotes the activation of mTOR and its downstream targets, such as P70 ribosomal protein S6 kinase (S6K) and eukaryotic translation initiation factor 4E-binding protein 1 (4EBP1) [9]. In summary, activation of Akt leads to escalated protein synthesis in skeletal muscle.

The recovery processes of muscle mass during reloading are similar to those that occur after resistance exercise, as both excite protein synthesis in skeletal muscle and result in enhancement of muscle mass. Therefore, we measured the factors of the mTOR signal. First, we analyzed the level of Akt phosphorylation in the soleus muscle of RE5 and RE10. In the RE5 group, the phosphorylation level of Akt of RE5_E80 was significantly increased (Figure 3a). Next, we evaluated the phosphorylation levels of S6K and 4EBP1. In the RE5 group, the phosphorylation level of S6K significantly increased in the soleus muscle of RE5_E80 (Figure 3b), but that of 4EBP1 did not increase (Figure 3c). As S6 is a direct target of S6K [24], the phosphorylation level of S6 was measured. Similar to that of S6K, the phosphorylation level of S6 was greater than in RE5_E80 in the soleus muscle, but not significantly $(p=0.06)$ (Figure 3d). In regard to other factors, glycogen synthase kinase 3 beta (GSK3 $\beta$ ) and $5^{\prime}$ adenosine monophosphate-activated protein kinase (Ampk), no change was observed in the phosphorylation levels (Figure 3e,f). These data indicate that E80 intake promotes the phosphorylation 
of Akt, S6K in reloaded soleus muscle in the RE5 group. In the RE10 group, there are no differences between Normal and E80 groups in all six proteins.

a

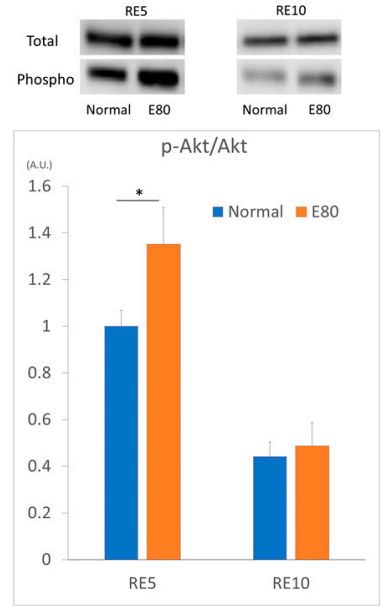

d

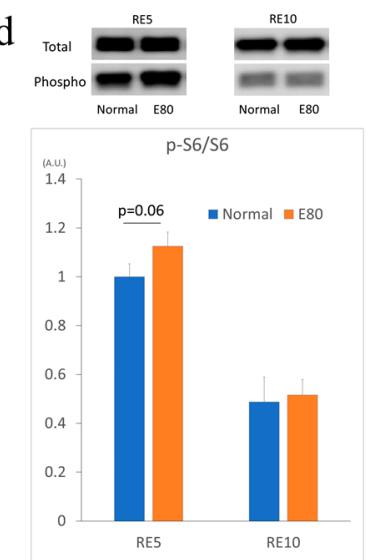

b

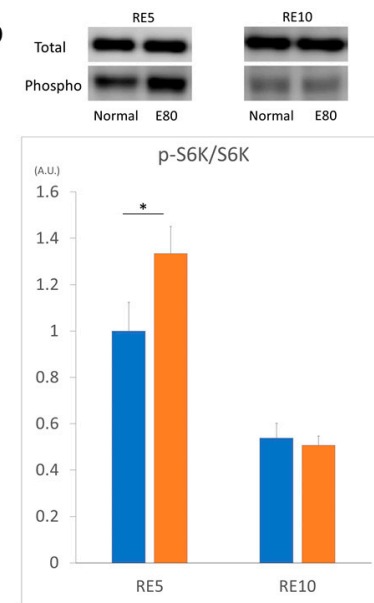

e

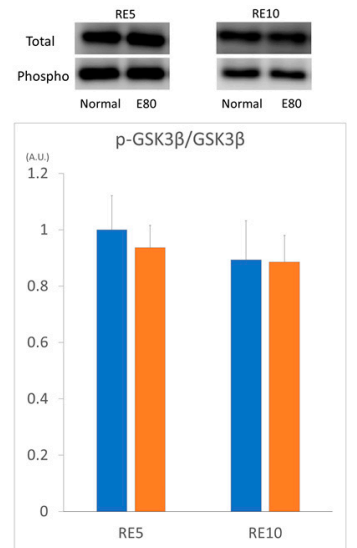

c

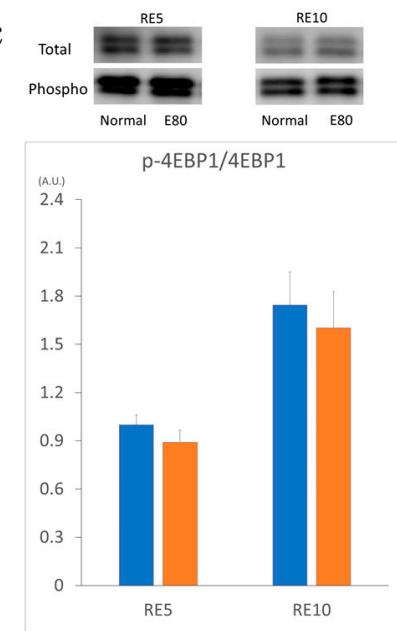

f

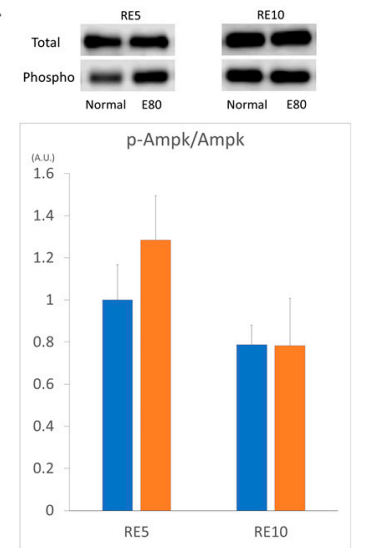

Figure 3. E80 activated Akt/mTOR pathway signaling. Western blot bands of total and phosphorylated protein (above) and relative ratio of phosphorylated protein/total protein (below) of soleus muscle proteins using antibodies against p-Akt (thr) and Akt (a), p-P70 ribosomal protein S6 kinase (S6K) and S6K (b), p-eukaryotic translation initiation factor 4E-binding protein 1 (4EBP1) and 4EBP1 (c), p-S6 and S6 (d), p-glycogen synthase kinase 3 beta (GSK3b) and GSK3b (e), and p-5' adenosine monophosphate-activated protein kinase (Ampk) and Ampk (f). Soleus muscle was prepared on the RE5 and RE10 groups. Quantitative data represent mean \pm SEM. * indicates significant difference $(p<0.05)(n=6-7)$.

\subsection{E80 Stimlated S6K and S6 Phospholyration In Vitro}

Finally, we evaluated whether E80 has the potential to affect skeletal muscle cell directly in vitro. We used cultured skeletal muscle cell C2C12 myoblasts. Differentiated C2C12 forms myotubes were treated with two different E80 concentrations $(10 \mu \mathrm{g} / \mathrm{mL}$ or $30 \mu \mathrm{g} / \mathrm{mL})$ for $6 \mathrm{~h}, 12 \mathrm{~h}$, and $24 \mathrm{~h}$. Firstly, we analyzed the level of Akt phosphorylation in C2C12 myotubes. Akt phosphorylation level declined in myotubes treated with $10 \mu \mathrm{g} / \mathrm{mL}$ E80 for $6 \mathrm{~h}$ (Figure 4a). The Akt phosphorylation in myotubes treated with $30 \mu \mathrm{g} / \mathrm{mL}$ E80 did not change compared with that in the $6 \mathrm{~h}$ control group (Figure 4a). There is no difference of Akt phosphorylation level in $12 \mathrm{~h}$ or $24 \mathrm{~h}$ group between the control and E80 groups (Figure 4a). Next, we evaluated the phosphorylation levels of S6K in myotubes. The phosphorylation level of S6K significantly increased in myotubes treated with $30 \mu \mathrm{g} / \mathrm{mL}$ E80 for $6 \mathrm{~h}$ (Figure 4b). However, that in myotubes treated with $10 \mu \mathrm{g} / \mathrm{mL}$ E80 did not change (Figure $4 \mathrm{~b}$ ). There is no difference in $12 \mathrm{~h}$ or $24 \mathrm{~h}$ group between the control and E80 groups (Figure $4 \mathrm{~b}$ ). Concerning the phosphorylation level of $\mathrm{S} 6$, that in myotubes treated with $10 \mu \mathrm{g} / \mathrm{mL}$ E80 for $6 \mathrm{~h}$ was greater than that for $6 \mathrm{~h}$ control (Figure $4 \mathrm{c}$ ). 
Similarly, those in myotubes treated with $10 \mu \mathrm{g} / \mathrm{mL}$ and $30 \mu \mathrm{g} / \mathrm{mL}$ for $12 \mathrm{~h}$ increased compared with that in $12 \mathrm{~h}$ control (Figure 4c). However, these differences disappeared in the $24 \mathrm{~h}$ groups (Figure $4 \mathrm{c}$ ).

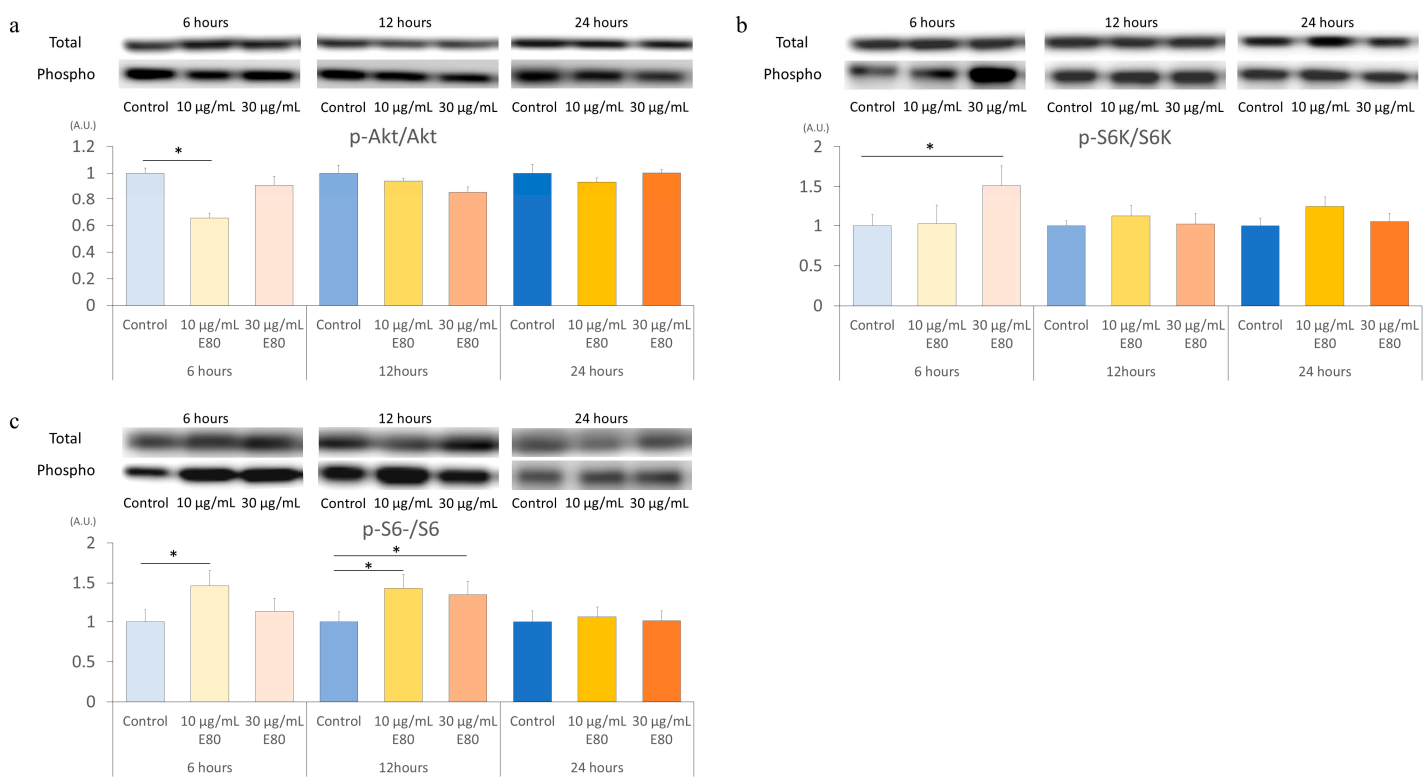

Figure 4. E80 stimulated S6K and S6 phosphorylation in vitro. C2C12 myotubes treated with $10 \mu \mathrm{g} / \mathrm{mL}$ or $30 \mu \mathrm{g} / \mathrm{mL}$ of E80. Western blot bands of total and phosphorylated protein (above) and relative ratio of phosphorylated protein/total protein (below) of differentiated $\mathrm{C} 2 \mathrm{C} 12$ myotubes proteins using antibodies against p-Akt (thr) and Akt (a), p-S6K and S6K (b), and p-S6 and S6 (c). Quantitative data represent mean \pm SEM. * indicates significant difference $(p<0.05)(n=5-6)$.

\section{Discussion}

We observed that supplementation of E80 does not prevent muscle atrophy induced by HU (Figure 2a-d), but it promotes recovery of muscle mass and the phosphorylation of Akt and S6K when reloading (Figure $3 a, b)$.

E80 administration promoted recovery of the soleus wet mass, soleus wet mass/body weight ratio, and the CSA compared with those in Normal. However, these indicators did not restore to the level of those in the 12-week control (equivalent age to RE10). As previously reported, the soleus wet mass, soleus wet mass/body weight ratio did not recover to the control level after 7 days of reloading, but they recovered after 14 days of reloading $[17,25]$. In addition, the CSA did not recover to the control level after 14 days of reloading, but they recovered after 28 days of reloading $[17,25]$. The reason that these indicators did not return to basal control level is that the mice body weight did not recover to basal control level after several days. This occurred because stimulation of hindlimb muscle is a mechanical load from the body weight of mice. In this experiment, mice body weight also did not recover to basal control during the 10 days of reloading (Figure 1a).

Akt is a crucial regulator of skeletal muscle hypertrophy [26]. Akt induces activation of mTOR, which activates S6K [26]. Furthermore, the levels of phosphorylated S6K correlate with the magnitude of skeletal muscle hypertrophy after resistance training [26]. Akt and S6K were significantly activated in RE5_E80 compared with RE5_Normal. Additionally, although it is not significant, S6 was seemingly activated. According to these results, E80 promoted protein synthesis during reloading and resulted in a fast recovery of muscle mass from HU-induced atrophy compared with Normal. Additionally, dominant-negative Ampk transgenic mice in which a dominant-negative Ampk $\alpha 2$ subunit was overexpressed under the muscle creatine kinase promoter (expressed in heart and skeletal muscle) showed that EDL muscles tended to be larger than in wild-type mice, suggesting that Ampk might negatively regulate basal muscle mass [27]. However, in this experiment, we did not observe activation of Ampk (Figure 3f). 
The phosphorylation level of Akt, S6K, and S6 did not differ between E80 and Normal in the RE10 group. Some reports showed that the phosphorylation level of these proteins reached the highest after approximately three days of reloading and declined gradually until it returned to normal. It is possible that these proteins were activated in RE10_E80 if they were analyzed during days 2 to 3 of reloading. In vitro experiment, the phosphorylation level of Akt decreased with $10 \mu \mathrm{g} / \mathrm{mL}$ of E80 for the $6 \mathrm{~h}$ treatment group (Figure 4a). However, the phosphorylation level of S6K seemed to be activated with $30 \mu \mathrm{g} / \mathrm{mL}$ of E80 for the $6 \mathrm{~h}$ treatment group (Figure $4 \mathrm{~b}$ ). Likewise, the phosphorylation level of S6 with $10 \mu \mathrm{g} / \mathrm{mL}$ of E80 for the $6 \mathrm{~h}$ treatment group was increased, as well as those with $10 \mu \mathrm{g} / \mathrm{mL}$ and $30 \mu \mathrm{g} / \mathrm{mL}$ of E80 for the $12 \mathrm{~h}$ treatment groups (Figure $4 \mathrm{c}$ ).

Administration of E80 did not prevent muscle atrophy induced by HU. We previously assessed whether E80 prevented denervation-induced muscle atrophy. Similar to this experiment, E80 did not block the reduction of muscle mass (Figure S1a,b). We also analyzed the mRNA expression level of ubiquitin ligase regulating muscle atrophy, such as Murf1 and MAFbx, during one week of denervation, but these gene mRNA expression levels did not change between Normal and E80 (Figure S1c,d). However, in this experiment, we showed that E80 promoted recovery of muscle mass during reloading. Also, E80 stimulated the phosphorylation level of Akt and S6K after five days of reloading. In addition to in vivo experiments, E80 also activated S6K or S6 in C2C12 myotubes (Figure 4b,c). Depending on the concentration or duration of treatment, E80 increased the phosphorylation level of these proteins. In vitro and in vivo experiments are not comparable simply, but we think E80 has the potential for increasing phosphorylation levels of S6K and S6, and encouraging muscle mass recovery and could be a useful supplemental candidate for restoring skeletal muscle mass after inactivity or injury. Also, it may play a role in human skeletal muscle development.

It is not accessible to activate S6K of skeletal muscle in elderly men with resistance training, because S6K phosphorylation does not increase the rate of protein synthesis in elderly men compared with younger men [28]. These facts indicate that it is difficult for elderly men to enhance signal transmission in the cell and to increase protein synthesis. The main cause of sarcopenia is considered to be the gradual loss of muscle mass and function [29,30]. If E80 promotes S6K phosphorylation and protein synthesis in aged people, it may be an optimal supplement for maintaining or restoring muscle mass caused by sarcopenia. For practical utilization of E80 as a supplement for both elderly men and athletes, further studies to appraise the effect of E80 on aged mice or aged humans are important.

\section{Materials and Methods}

\subsection{HU and Reloading}

All animal experiment procedures were performed in accordance with the institutional guidelines for the care and use of laboratory animals as approved by the University of Tsukuba (No 18-357). Animals were subjected to $\mathrm{HU}$ according to a previously described method [31]. Male C57BL/6J mice were utilized (Charles River Laboratories Japan, Kanagawa, Japan). Mice were maintained at $22 \sim 25^{\circ} \mathrm{C}$, and kept on a 12/12-h light/dark cycle. Mice were housed in cylindrical enclosures (18 $\mathrm{cm}$ in diameter). At day 0 , mice assigned to the HU group $(n=7)$ were unloaded. Under isoflurane anesthesia $(2 \% \sim 3 \%)$, bandage tapes were braided around the tail with a paper clip and a swivel hook. The metal string was thread through the swivel hook and fixed to the top of the cage to suspend the hindlimbs of the mice. Mice toes were kept lifted about $3 \mathrm{~cm}$ from the bottom in order that their feet not touch the cage floor. Each suspended mouse could move freely, using its forelimbs over the entire floor area of the cage. After two weeks of $\mathrm{HU}$, mice were released from suspension and their hindlimb muscles were reloaded. Food and water were available ad libitum during the entire experimental period. Mice were allowed to acclimate to their cages for one week before experiments commenced. After the prescribed procedure, mice were anesthetized with isoflurane and subsequently sacrificed. The soleus muscle was carefully dissected, wet mass measured immediately, and frozen in liquid nitrogen. They were stored at $-80^{\circ} \mathrm{C}$ until use. 


\subsection{Cell Culture and Treatment}

All cell culture experiments were performed in a humidified environment at $37^{\circ} \mathrm{C}$ in $5 \% \mathrm{CO}_{2}$. The skeletal muscle cell lineage C2C12 myoblasts were proliferated in Dulbecco's modified eagle's medium (DMEM) (Life Technologies Corporation, New York, United States of America) supplemented with $10 \%$ fetal bovine serum (FBS) and penicilin-streptomicin up to $50 \%$ confluency in six-well plate (BM Equipment Co., Ltd., Tokyo, Japan). When cells reached $80 \%$ confluency, serum content in culture medium was switched from $10 \%$ FBS to $2 \%$ horse serum so as to induce the differentiation of myoblasts into myotubes. After seven days of differentiation, myotubes were stimulated with each concentration of E80 $(10 \mu \mathrm{g} / \mathrm{mL}$ and $30 \mu \mathrm{g} / \mathrm{mL})$ for $6 \mathrm{~h}, 12 \mathrm{~h}$, and $24 \mathrm{~h}$. E80 was dissolved in 100\% dimethyl sulfoxide (DMSO), of which the final concentration was prepared for $0.1 \%$ in serum free DMEM. The series of experiments was repeated two times using different passages of $\mathrm{C} 2 \mathrm{C} 12$ myotubes.

\subsection{Preparation and Storage of E80 from Black Tea}

Black tea (30 g; Daily club; Mitsui Norin Co., Ltd., Tokyo, Japan) was seethed for 1 min in boiling water $(1000 \mathrm{~mL})$, and then allowed to stand for $10 \mathrm{~min}$. The brew was filtered using double-layered filter paper (number 2; Advantec, Toyo Roshi Kaisha, Tokyo, Japan). The filtrate was mixed with $250 \mathrm{~mL}$ Toyopearl HW-40F (Tosoh, Tokyo, Japan) previously washed with water. After 30 min, Toyopearl HW-40F was filtered using a filter paper and washed 10 times with $150 \mathrm{~mL}$ of water. Polyphenolic substances adsorbed to the Toyopearl resin were extracted 12 times with $150 \mathrm{~mL}$ of $80 \%(v / v)$ warm ethanol. All extracts were evaporated under reduced pressure and freeze dried to yield $2.96 \mathrm{~g}$. This dark brown powder was named E80. The sample was stored in the dark and under $20^{\circ} \mathrm{C}$ until use.

\subsection{Quantitative Analysis of Caffeine, Catechins, and Theaflavins in E80}

High performance liquid chromatography (HPLC) analysis was executed using the Inertsil ODS-3 column $(4.6 \times 250 \mathrm{~mm}, 5 \mu \mathrm{m}$; GL Sciences, Tokyo, Japan) attached to a Shimadzu Class M10A HPLC system (Shimadzu, Kyoto, Japan). The column was eluted at $40{ }^{\circ} \mathrm{C}$ with a linear gradient from $5 \%$ to $40 \%(v / v)$ acetonitrile containing $0.02 \%(v / v)$ trifluoroacetic acid over $70 \mathrm{~min}$ at a flow rate of $0.7 \mathrm{~mL} / \mathrm{min}$ and monitored for absorbance at $280 \mathrm{~nm}$. Quantitative determination was based on the calibration curve prepared with an adequate concentration of a pure commercial standard of caffeine, catechins, and theaflavins. Samples were dissolved in $10 \%(v / v)$ acetonitrile and $4.0 \mu \mathrm{L}$ portions were injected into the column.

\subsection{Quantitative Analysis of Highly Polymerized Polyphenols in E80}

For preparation of the analytical sample from E80, $382 \mathrm{mg}$ of E80 was dissolved in water (100 mL). The solution was extracted eight times with $40 \mathrm{~mL}$ ethyl acetate to remove the ethyl acetate-soluble constituents. The water phase was evaporated under reduced pressure to remove the ethyl acetate in the solution and the $\mathrm{pH}$ was adjusted to 3 with hydrochloric acid $(\mathrm{HCl})$. The solution was then extracted five times with $40 \mathrm{~mL}$ n-butanol. The aqueous phase of $\mathrm{n}$-butanol was concentrated under reduced pressure at $50^{\circ} \mathrm{C}$ and freeze dried. The yield was $140 \mathrm{mg}$.

For quantitative analysis of the highly polymerized polyphenols in E80, we used the following analytical instruments that consisted of two medium-pressure SP-11 delivery pumps (Tokyo Rika Kikai, Tokyo, Japan), a gradient mixer, a sample injector VI-II (EYELA), an intermediate pressure glass column $(1 \times 30 \mathrm{~cm})$ packed with Toyopearl HW-40F, and a fraction collector CHF161RA (Advantec, Tokyo, Japan). The analytical sample $(1.7 \mathrm{~mL})$ was dissolved in $20 \%(v / v)$ acetone and injected into the column, which was conditioned with $20 \%$ acetone. The column was eluted using a linear gradient containing from $20 \%$ to $50 \%$ acetone (total volume $180 \mathrm{~mL}$ ) at a flow rate of $0.4 \mathrm{~mL} / \mathrm{min}$. The eluent $(1.5 \mathrm{~g}$ ) was collected by a fraction collector and the absorbance was measured at $350 \mathrm{~nm}$. From the elution profile, the highly polymerized polyphenol fractions were combined, evaporated under reduced pressure, freeze dried, and then weighed. 


\subsection{Diet Preparation}

Mice of the normal diet group were fed with a powdered diet (NMF; Oriental yeast Co., Tokyo, Japan), and those in the E80 group were fed with NMF containing 0.5\% E80. Seven groups were prepared: non-treated mice eating only NMF (control), unloaded mice for two weeks eating only NMF (HU_Normal), unloaded mice eating NMF mixed with E80 (HU_E80), reloaded mice for five days eating only NMF (RE5_Normal), reloaded mice for five days eating NMF including E80 (RL5_E80), reloaded mice for 10 days eating only NMF (RE10_Normal group), and reloaded mice for 10 days eating NMF including E80 (RE10_E80 group).

\subsection{Antibodies}

We used the following antibodies: anti-Akt (No. 9272), anti-phospho-Akt (Ser473; No. 9271), anti-S6K (No. 9202), anti-phospho-S6K (Thr389; No. 9205), anti-S6 (No. 2217), anti-phospho-S6 (Ser235/236; No. 4858), anti-4EBP1 (No. 9644), anti-phospho-4EBP1 (Thr37/46; No. 2855), anti-GSK3 $\beta$ (No. 12456), anti-phospho-GSK3ß (Ser9; No. 5558), anti-Ampk (No. 2532), anti-phospho-Ampk (Ser9; No. 2535), anti-mouse IgG (No. 7076), and anti-rabbit IgG (No. 7074) purchased from Cell Signaling Technology (Massachusetts, United States of America). Anti- $\alpha$-Tubulin (12G10) was purchased from DSHB (Iowa, United States of America). Anti- Laminin $\alpha-2$ (SC-59854) was purchased from Santa Cruz Biotechnology (Texas, United States of America).

\subsection{CSA Quantification}

Dissected soleus muscle was soaked in optimal cutting temperature compound (Sakura Finetek, Tokyo, Japan), and then immediately frozen in isopentane iced with liquid nitrogen and stored at $-30{ }^{\circ} \mathrm{C}$ until sectioning. Frozen muscle samples were sectioned at a thickness of $12 \mu \mathrm{m}$, air dried, and stored at $-30^{\circ} \mathrm{C}$. Images were captured with the BZ-X710 microscope (Keyence, Osaka, Japan).

To verify the CSA of muscle fibers, the muscle sections were incubated overnight with Laminin alpha2 antibody to stain the sarcolemma.

Subsequently, the sections were incubated with Alexa for $90 \mathrm{~min}$ and then washed with Tris-buffered saline with Tween 20 (TBS-T, $50 \mathrm{mM}$ Tris ( $\mathrm{pH}=7.4$ ), $138 \mathrm{mM} \mathrm{NaCl}, 2.7 \mathrm{mM} \mathrm{KCl}$, and $0.05 \%$ Tween 20 ) three times for $5 \mathrm{~min}$. The stained sections were observed under the BZ-X710 microscope and CSA analysis was carried out using the BZ-X Analyzer (Keyence).

\subsection{Western Blot Analysis}

To prepare total protein lysate, frozen muscle samples were homogenized in lysis buffer (1\% Nonidet-P40, 1\% sodium deoxycholate, $0.2 \%$ sodium dodecyl sulfate(SDS), $150 \mathrm{mM}$ $\mathrm{NaCl}, 50 \mathrm{mM}$ 4-(2-hydroxyethyl)-1-piperazineethanesulfonic acid (HEPES) ( $\mathrm{pH}=7.5$ ), $10 \mathrm{mM}$ ethylenediaminetetraacetic acid (EDTA), $10 \mathrm{mM} \mathrm{NaF}, 10 \mathrm{mM} \mathrm{Na} \mathrm{P}_{2} \mathrm{O}_{7}$, and $2 \mathrm{mM} \mathrm{Na}_{3} \mathrm{VO}_{4}$ ) supplemented with $1 \%$ protease inhibitor cocktail for mammalian tissues (No. 162-0177; Nacalai Tesque, Kyoto, Japan). The concentration of protein was determined by the bicinchoninic acid method using the Protein Assay Bicinchoninate Kit (No. 297-73101, Wako, Osaka, Japan). Protein extracts were electrophoresed on appropriate concentration $(7.5 \%-15.0 \%)$ of acrylamide gels and subsequently transferred to polyvinylidene difluoride membranes (PVDF; No. 162-0177; Bio-Rad, California, United States of America). The PVDF membranes were blocked with 5\% skim milk in Tris Buffered Saline with Tween 20 (TBS-T) for $45 \mathrm{~min}$ at room temperature $\left(20 \sim 25^{\circ} \mathrm{C}\right)$ and then incubated overnight with primary antibody at $4{ }^{\circ} \mathrm{C}$. Subsequently, the membrane was incubated with anti-rabbit IgG for $90 \mathrm{~min}$. The intensity of proteins was evaluated using the LI-COR system (No. CDG002134) and quantified by Image Studio Digits 4.0 software (Nacalai Tesque). 


\subsection{Statistical Analysis}

A one-way analysis of variance (ANOVA) was performed using SPSS software (IBM Corp., New York, United States of America) to determine whether a significant interaction existed between the two independent factors.

Supplementary Materials: The following are available online at http://www.mdpi.com/2072-6643/11/9/2131/s1, Figure S1: E80 did not prevent denervation-induced atrophy and gene expression concerning muscle atrophy.

Author Contributions: Y.A. and T.T. conceived and designed the experiments; Y.A. and T.O. performed the experiments and analyzed the data; O.N. contributed to guiding the experiment; Y.A. wrote the manuscript.

Funding: This work was supported by research grant from the University of Tsukuba.

Acknowledgments: We thank K. Takeda for help with the advice and the animal work.

Conflicts of Interest: The authors declare no conflict of interest.

\section{Abbreviations}

$\begin{array}{ll}\text { 4EBP1 } & \text { Eukaryotic translation initiation factor 4E-binding protein } 1 \\ \text { Ampk } & 5^{\prime} \text { adenosine monophosphate-activated protein kinase } \\ \text { ANOVA } & \text { Analysis of variance } \\ \text { CSA } & \text { Cross sectional area } \\ \text { DMEM } & \text { Dulbecco's modified eagle's medium } \\ \text { DMSO } & \text { Dimethyl sulfoxide } \\ \text { EDTA } & \text { Ethylenediaminetetraacetic acid } \\ \text { EGCG } & \text { Epigallocatechin gallate } \\ \text { ER } & \text { Endoplasmic reticulum } \\ \text { FBS } & \text { Fetal bovine serum } \\ \text { GSK3 } \beta & \text { Glycogen synthase kinase 3 beta } \\ \text { HEPES } & \text { 4-(2-hydroxyethyl)-1-piperazineethanesulfonic acid } \\ \text { HPLC } & \text { High performance liquid chromatography } \\ \text { IGF } & \text { Insulin-like growth factors } \\ \text { mTOR } & \text { Mammalian target of rapamycin } \\ \text { S6K } & \text { P70 ribosomal protein S6 kinase } \\ \text { SDS } & \text { Sodium dodecyl sulfate } \\ \text { PVDF } & \text { Polyvinylidene difluoride } \\ \text { S6 } & \text { Ribosomal protein S6 kinase }\end{array}$

\section{References}

1. Weisburger, J.H. Tea and health: A historical perspective. Cancer Lett. 1997, 114, 315-317. [CrossRef]

2. Toschi, T.G.; Bordoni, A.; Hrelia, S.; Bendini, A.; Lercker, G.; Biagi, P.L. The protective role of different green tea extracts after oxidative damage is related to their catechin composition. J. Agric. Food Chem. 2000, 48, 3973-3978. [CrossRef] [PubMed]

3. Murase, T.; Haramizu, S.; Shimotoyodome, A.; Nagasawa, A.; Tokimitsu, I. Green tea extract improves endurance capacity and increases muscle lipid oxidation in mice. Am. J. Physiol. Regul. Integr. Comp. Physiol. 2005, 288, R708-R715. [CrossRef] [PubMed]

4. Ueda-Wakagi, M.; Nagayasu, H.; Yamashita, Y.; Ashida, A.H. Green tea ameliorates hyperglycemia by promoting the translocation of glucose transporter 4 in the skeletal muscle of diabetic rodents. Int. J. Mol. Sci. 2019, 20, 2436. [CrossRef] [PubMed]

5. Rodriguez, J.; Gilson, H.; Jamart, C.; Naslain, D.; Pierre, N.; Deldicque, L.; Francaux, M. Pomegranate and green tea extracts protect against er stress induced by a high-fat diet in skeletal muscle of mice. Eur. J. Nutr. 2015, 54, 377-389. [CrossRef]

6. Alway, S.E.; Bennett, B.T.; Wilson, J.C.; Edens, N.K.; Pereira, S.L. Epigallocatechin-3-gallate improves plantaris muscle recovery after disuse in aged rats. Exp. Gerontol. 2014, 50, 82-94. [CrossRef] [PubMed] 
7. Meador, B.M.; Mirza, K.A.; Tian, M.; Skelding, M.B.; Reaves, L.A.; Edens, N.K.; Tisdale, M.J.; Pereira, S.L. The green tea polyphenol epigallocatechin-3-gallate (EGCg) attenuates skeletal muscle atrophy in a rat model of sarcopenia. J. Frailty Aging 2015, 4, 209-215.

8. Stewart, C.E.; Rittweger, J. Adaptive processes in skeletal muscle: Molecular regulators and genetic influences. J. Musculoskelet. Neuronal Interact. 2006, 6, 73-86.

9. Fernandes, T.; Ursula, S.P.R.; Stephano, M.F.S.; Cleber, A.R.; Edilamaar, O.M. Signaling Pathways That Mediate Skeletal Muscle Hypertrophy: Effects of Exercise Training; INTECH Open Access Publisher: London, UK, 2012.

10. Dirks, M.L.; Wall, B.T.; van de Valk, B.; Holloway, T.M.; Holloway, G.P.; Chabowski, A.; Goossens, G.H.; van Loon, L.J. One week of bed rest leads to substantial muscle atrophy and induces whole-body insulin resistance in the absence of skeletal muscle lipid accumulation. Diabetes 2016, 65, 2862-2875. [CrossRef]

11. Vandenburgh, H.; Chromiak, J.; Shansky, J.; Del Tatto, M.; Lemaire, J. Space travel directly induces skeletal muscle atrophy. FASEB J. 1999, 13, 1031-1038. [CrossRef]

12. Globus, R.K.; Morey-Holton, E. Hindlimb unloading: Rodent analog for microgravity. J. Appl. Physiol. (1985) 2016, 120, 1196-1206. [CrossRef] [PubMed]

13. Fitts, R.H.; Riley, D.R.; Widrick, J.J. Functional and structural adaptations of skeletal muscle to microgravity. J. Exp. Biol. 2001, 204, 3201-3208. [PubMed]

14. Adams, G.R.; Caiozzo, V.J.; Baldwin, K.M. Skeletal muscle unweighting: Spaceflight and ground-based models. J. Appl. Physiol. (1985) 2003, 95, 2185-2201. [CrossRef] [PubMed]

15. Powers, S.K.; Lynch, G.S.; Murphy, K.T.; Reid, M.B.; Zijdewind, I. Disease-induced skeletal muscle atrophy and fatigue. Med. Sci. Sports Exerc. 2016, 48, 2307-2319. [CrossRef] [PubMed]

16. Kortebein, P.; Symons, T.B.; Ferrando, A.; Paddon-Jones, D.; Ronsen, O.; Protas, E.; Conger, S.; Lombeida, J.; Wolfe, R.; Evans, W.J. Functional impact of 10 days of bed rest in healthy older adults. J. Gerontol. A Biol. Sci. Med. Sci. 2008, 63, 1076-1081. [CrossRef] [PubMed]

17. Xia, L.; Cheung, K.K.; Yeung, S.S.; Yeung, E.W. The involvement of transient receptor potential canonical type 1 in skeletal muscle regrowth after unloading-induced atrophy. J. Physiol. 2016, 594, 3111-3126. [CrossRef]

18. Aoki, Y.; Ozawa, T.; Takemasa, T.; Numata, O. Black tea high-molecular-weight polyphenol-rich fraction promotes hypertrophy during functional overload in mice. Molecules 2017, 22, 548. [CrossRef]

19. Campana, C.; Griffin, P.L.; Simon, E.L. Caffeine overdose resulting in severe rhabdomyolysis and acute renal failure. Am. J. Emerg. Med. 2014, 32, 111-e3. [CrossRef]

20. Li, S.; Lo, C.Y.; Pan, M.H.; Lai, C.S.; Ho, C.T. Black tea: Chemical analysis and stability. Food Funct. 2013, 4, 10-18. [CrossRef]

21. Makila, L.; Laaksonen, O.; Alanne, A.L.; Kortesniemi, M.; Kallio, H.; Yang, B. Stability of hydroxycinnamic acid derivatives, flavonol glycosides, and anthocyanins in black currant juice. J. Agric. Food Chem. 2016, 64, 4584-4598. [CrossRef]

22. Bodine, S.C. Disuse-induced muscle wasting. Int. J. Biochem. Cell Biol. 2013, 45, 2200-2208. [CrossRef] [PubMed]

23. Mitchell, P.O.; Pavlath, G.K. A muscle precursor cell-dependent pathway contributes to muscle growth after atrophy. Am. J. Physiol. Cell Physiol. 2001, 281, C1706-C1715. [CrossRef] [PubMed]

24. Kirkendall, D.T.; Garrett, W.E., Jr. The effects of aging and training on skeletal muscle. Am. J. Sports Med. 1998, 26, 598-602. [CrossRef] [PubMed]

25. Zhang, B.T.; Yeung, S.S.; Cheung, K.K.; Chai, Z.Y.; Yeung, E.W. Adaptive responses of TRPC1 and TRPC3 during skeletal muscle atrophy and regrowth. Muscle Nerve 2014, 49, 691-699. [CrossRef] [PubMed]

26. Baar, K.; Esser, K. Phosphorylation of $\mathrm{p} 70^{\mathrm{s} 6 \mathrm{k}}$ correlates with increased skeletal muscle mass following resistance exercise. Am. J. Physiol. 1999, 276, C120-C127. [CrossRef]

27. Thomson, D.M. The role of AMPK in the regulation of skeletal muscle size, hypertrophy, and regeneration. Int. J. Mol. Sci. 2018, 19, 3125. [CrossRef]

28. McGee, S.L.; Mustard, K.J.; Hardie, D.G.; Baar, K. Normal hypertrophy accompanied by phosphoryation and activation of AMP-activated protein kinase alpha1 following overload in LKB1 knockout mice. J. Physiol. 2008, 586, 1731-1741. [CrossRef]

29. Evans, W.J. Skeletal muscle loss: Cachexia, sarcopenia, and inactivity. Am. J. Clin. Nutr. 2010, 91, 1123S-1127S. [CrossRef] 
30. Fielding, R.A.; Vellas, B.; Evans, W.J.; Bhasin, S.; Morley, J.E.; Newman, A.B.; Abellan van Kan, G.; Andrieu, S.; Bauer, J.; Breuille, D.; et al. Sarcopenia: An undiagnosed condition in older adults. Current consensus definition: Prevalence, etiology, and consequences. International working group on sarcopenia. J. Am. Med. Dir. Assoc. 2011, 12, 249-256. [CrossRef]

31. Spangenburg, E.E.; Booth, F.W. Leukemia inhibitory factor restores the hypertrophic response to increased loading in the lif(-/-) mouse. Cytokine 2006, 34, 125-130. [CrossRef]

(C) 2019 by the authors. Licensee MDPI, Basel, Switzerland. This article is an open access article distributed under the terms and conditions of the Creative Commons Attribution (CC BY) license (http://creativecommons.org/licenses/by/4.0/). 